\title{
Nasal mucociliary transport is impaired at altitude
}

\author{
P.W. Barry*+, N.P. Mason**+, C. O'Callaghan*
}

Nasal mucociliary transport is impaired at altitude. P.W. Barry, N.P. Mason, C. O'Callaghan. @eERS Journals Ltd 1997.

ABSTRACT: There have been a number of anecdotal reports of rhinitis and nasal obstruction occurring at altitude. To quantify these reports, we investigated nasal obstruction and mucociliary transport in a group of healthy volunteers trekking to Mount Everest Base Camp, Nepal, altitude 5,300 m.

Nasal obstruction was estimated by subjective scoring and mucociliary transport was determined by the saccharin method.

Subjective assessment showed that nasal obstruction was increased on arrival at $5,300 \mathrm{~m}$ in 23 out of 54 subjects, unchanged in 24, and decreased in seven (McNemar's test: $\chi^{2}=7.5 ; \mathbf{p}<0.01$ ). The median saccharin time at sea level was 11 min $(95 \%$ confidence interval $(95 \% \mathrm{CI}) 8-17 \mathrm{~min})$ and increased to $60 \mathrm{~min}(95 \%$ CI 27-60 min) on arrival at $5,300 \mathrm{~m}$. Compared to sea level, the saccharin time was prolonged in 25 out of 33 subjects $\left(\right.$ McNemar's test: $\chi^{2}=14.7 ; \mathbf{p}<0.01$ ), and remained prolonged after 2 weeks at altitude (median $60 \mathrm{~min} ; 95 \%$ CI 38-60 min).

These results confirm the subjective feelings of nasal obstruction and show that nasal mucociliary transport times are increased at altitude. The mechanisms of these findings are not clear, but nasal obstruction may impede breathing and adversely affect performance at altitude.

Eur Respir J., 1997; 10: 35-37.
*Dept of Child Health, University of Leicester, Leicester, UK. **Service D'AnesthèsieRèanimation, Hôpital Henri Mondor, Paris, France. ${ }^{+}$British Mount Everest Medical Expedition, The Pinfolds, Hyssington, Powys, UK.

Correspondence: P.W. Barry

Dept of Child Health

University of Leicester

Clinical Sciences Building

Leicester Royal Infirmary

PO Box 65

Leicester LE2 7LX

UK

Keywords: Altitude, mucociliary function, nasal obstruction, saccharin time

Received: March 151996

Accepted after revision August 111996

PWB is funded by the Astra Foundation.
The upper respiratory tract conditions inspired air, and recovers heat and water during expiration [1]. If the nose is partially blocked, the work of breathing is increased [2] and mouth breathing may occur, which increases respiratory heat and water loss [1]. Despite anecdotal reports of nasal mucosal damage in mountaineers and climbers $[3,4]$, there have been no previous studies of nasal mucociliary function at altitude. Travellers to high altitude are subjected to severe environmental conditions, and the increase in respiratory minute volume associated with exposure to hypobaric hypoxia increases the amount of air that needs to be conditioned [5]. In a group of lowlanders travelling to an altitude of $5,300 \mathrm{~m}$, we measured subjective feelings of nasal blockage and nasal mucociliary function.

\section{Methods}

\section{Subjects}

Members of the British Mount Everest Medical Expedition were studied in the United Kingdom and in Nepal when they trekked from an altitude of 2,800 $\mathrm{m}$ to Mount Everest Base Camp $(5,300 \mathrm{~m})$ over 2 weeks. Subjects were studied on three occasions. Firstly, in the UK before the expedition; secondly, on arrival at Mount Everest Base Camp; and, where climbing itineries in the Everest region allowed, after 2 weeks acclimatization at altitudes of 5,000 $\mathrm{m}$ and above.

We studied 57 members of the expedition, 18 females and 39 males aged 15-55 yrs. None had a history of nasal trauma or surgery or were taking nasal medication. There were 4 smokers.

\section{Nasal score}

Fifty four subjects recorded their nasal obstruction score, a subjective measure of nasal blockage. Subjects occluded one nostril, inhaled through the nose and record their nasal obstruction as: patent (fully open) $=0$ points; partially blocked $=1$ point; or blocked $=2$ points. The procedure was then repeated for the other nostril, giving a possible total score of $0-4$ points.

\section{Saccharin test}

The saccharin test was undertaken as described by STANLEY et al. [6]. The time taken for the subject to perceive a sweet taste, representing transport of saccharin placed in the anterior part of the nose to the oropharynx, was noted. If no taste was experienced by $60 \mathrm{~min}$, the test was stopped. All saccharin tests were uncontrolled and not blinded, and were undertaken by the same researcher. The repeatability of the saccharin test was estimated by repeating the saccharin test on $26 \mathrm{sub}-$ jects after the expedition.

\section{Statistical analysis}

Nasal obstruction scores and saccharin times are expressed as medians and $95 \%$ confidence intervals for the median at each location. McNemar's test was used 
to determine if there was a significant number of subjects with increased nasal obstruction score or increased saccharin times at altitude. Spearman's rank correlation was used to estimate correlation between nasal obstruction scores and saccharin times. Wilcoxon's test was used to estimate the significance of the difference between repeated saccharin tests at sea level. Statistical significance was assumed at a probability of $5 \%$ or less.

The study was approved by the Leicestershire Ethics Review Committee, and written informed consent was obtained from the subjects.

\section{Results}

\section{Nasal obstruction}

The median nasal obstruction score before the expedition was 0 (range $0-2$ ). On arrival at $5,300 \mathrm{~m}$, the median nasal obstruction was 1 (range $0-3$ ). The nasal obstruction score was increased in 23 subjects and decreased in seven, a statistically significant increase in subjective assessment of nasal blockage on ascent to altitude (McNemar's test: $\left.\chi^{2}=7.5 ; \mathrm{p}<0.01\right)$.

\section{Saccharin Test}

At sea level, the median saccharin time was $11 \mathrm{~min}$ (95\% confidence interval (CI) 8-17 $\mathrm{min}$ ), rising to 60 $\min (95 \%$ CI $27-60 \mathrm{~min})$ on arrival at $5,300 \mathrm{~m}$. Saccharin times increased in 25 subjects and decreased in five (fig. 1), demonstrating a significant decrease in the nasal mucociliary transport rate (McNemar's test: $\chi^{2}=$ $14.7 ; \mathrm{p}<0.01)$. Saccharin times on arrival at base camp were not correlated with nasal obstruction scores $\left(r_{s}=\right.$ 0.096; $\mathrm{p}>0.05$ ). After acclimatization, the median saccharin time was $60 \mathrm{~min}$ (95\% CI 38-60 min), significantly

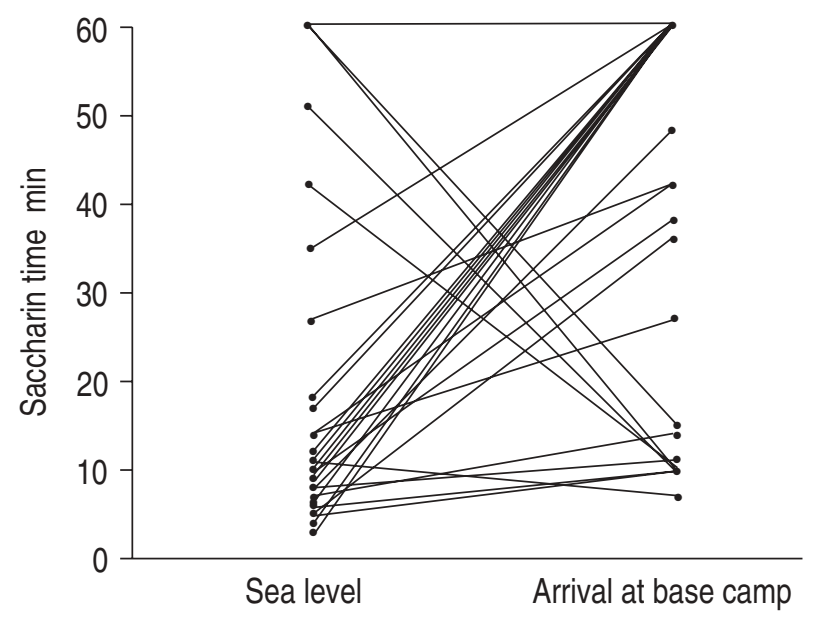

Fig. 1. - Paired saccharin times at sea level and on arrival at the base camp at $5,300 \mathrm{~m}$. A saccharin time of 60 min means that no saccharin was tasted at this time, and the test was terminated. There was a significant increase in sacharin time between the base camp (median $11 \mathrm{~min} ; 95 \%$ CI 8-17 min) and sea level (median $60 \mathrm{~min} ; 95 \%$ CI $27-60 \mathrm{~min})(\mathrm{p}<0.001) .95 \%$ CI: 95\% confidence interval. longer than at sea level (McNemar's test: $\left.\chi^{2}=13.4 ; \mathrm{p}<0.01\right)$. Compared to arrival at base camp, saccharin times were increased in five subjects after acclimatization and decreased in two.

Fifteen subjects reported symptoms of an upper respiratory tract infection in the month preceeding testing at altitude. The findings are unchanged if these subjects are removed from the analysis.

The median difference between paired saccharin times at sea level was $2.5 \mathrm{~min}$, (95\% CI 1-7.5 min), which was not statistically different from 0 (Wilcoxon statistic 170.5; $\mathrm{p}=0.15$ ).

\section{Discussion}

This observational study has shown an increase in the subjective assessment of nasal blockage, and a decrease in the nasal mucociliary transport rate, in a group of individuals ascending to altitude. No attempt was made to analyse the mechanisms underlying these findings, or their importance to performance at altitude. We postulate that the results may be due to the harsh environmental conditions at high altitude.

In controlled environments, others have shown changes in mucociliary transport only with very cold [7] or very dry [8] air. However, none of these studies have included the increase in minute ventilation which accompanies exposure to high altitude. The passage of large volumes of cold, dry air may overcome the ability of the nose to condition inspired air [9]. In vitro, hypoxia and hypercapnia impair mucociliary clearance $[10,11]$ but whether they account for the slowing of mucociliary function at altitude can only be surmised.

Partial nasal blockage increases the work of breathing at sea level [2], and encourages oral or oronasal breathing. Inspiration of cold air causes congestion of erectile tissue in the nose, to facilitate heat exchange with inspired and expired air [12], and increases nasal secretion $[13,14]$. This may lead to feelings of increased nasal blockage. Exercise at altitude is accompanied by very high levels of minute ventilation [5], and it is not known if nasal obstruction affects maximum work rates and performance at altitude. Furthermore, this study did not investigate nasal blockage per se, but rather subjective self-assessment of nasal blockage. Techniques such as posterior rhinomanometry [12] would have allowed us to make an objective assessment of nasal resistance.

Mountaineers have often reported sore noses and throats occurring at altitude, limiting their ability to climb [3, 4]. This study has confirmed that upper airway dysfunction occurs in mountaineers at altitude. Further studies are needed to determine the cause of the dysfunction, as far as possible controlling the environmental conditions, and the physiological changes that occur on exposure to high altitude.

Acknowledgements: The authors thank all members of the British Mount Everest Medical Expedition for their support. The British Mount Everest Medical Expedition is a registered charity. The authors thank N. Taub (Department of Epidemiology, University of Leicester) for statistical advice. 


\section{References}

1. Cole P. Modification of inspired air. In: Proctor DF, Andersen I, eds. The Nose: Upper Airway Physiology and the Atmospheric Environment. Amsterdam, Elsevier Biomedical Press, 1982; pp. 351-375.

2. Cole P, Niinimaa V, Mintz S, Silverman F. Work of nasal breathing: measurement of each nostril independently using a split mask. Acta Otolaryngol 1979; 88: 148-154.

3. Somerville TH. In: After Everest. London, Hodder and Stoughton, 1936; p. 132.

4. Unsworth H. In: Everest 2nd edn. London, Grafton, 1991; p. 165.

5. Ward MP, Milledge JS, West JB. In: High Altitude Medicine and Physiology. 2nd ed. London, Chapman \& Hall, 1995; pp. 221-225.

6. Stanley P, MacWilliam L, Greenstone M, Mackay I, Cole P. Efficacy of a saccharin test for screening to detect abnormal mucociliary clearance. $\mathrm{Br} J$ Dis Chest 1984; 78: 62-65.

7. Proctor DF, Anderson IB, Lundqvist GR. Human nasal mucosal function at controlled temperatures. Respir Physiol 1977; 30: 109-124.

8. Salah B, Dinh Xuan AT, Fouilladieu JL, Lockhart A, Regnard J. Nasal mucociliary transport in healthy subjects is slower when breathing dry air. Eur Respir $J$ 1988; 1: 852-855.

9. McFadden ER, Pichurko BM, Bowman HF, et al. Thermal mapping of the airways in humans. J Appl Physiol 1985; 58: 564-570.

10. Dalhamn T, Rosengren A. The effect of oxygen lack on tracheal ciliary activity. Arch Environ Health 1968; 16: 371-373.

11. Marin MG, Morrow PE. Effect of changing inspired $\mathrm{O}_{2}$ and $\mathrm{CO}_{2}$ levels on tracheal mucociliary transport rate. J Appl Physiol 1969; 27: 385-388.

12. Maran AGD, Lund VJ. In: Clinical Rhinology. New York, Theime Medical Publishers, 1990.

13. Philip G, Jankowski R, Baroody FM, Naclerio RM, Togias AG. Reflex activation of nasal secretion by unilateral inhalation of cold dry air. Am Rev Respir Dis 1993; 48: 1616-1622.

14. Silvers WS. The skiers nose. Ann Allergy 1991; 67: 32-36. 